\title{
EMPODERAMENTO: INSTRUMENTO DE EMANCIPAÇÃO SOCIAL? - UMA DISCUSSÃO CONCEITUAL
}

Rute Vivian Angelo Baquero

\begin{abstract}
Resumo
O texto problematiza a categoria empoderamento, discutindo os diferentes conceitos presentes na literatura, em termos dos objetivos perseguidos e das lógicas que os constituem. Com vistas a atingir este objetivo desenvolve um estudo de natureza teórica, que procura fundamentar-se, contudo, na análise de pesquisas empíricas, relatos de projetos objetivando ações empoderadoras e artigos de reflexão sobre o tema. Neste contexto, situa historicamente a origem do termo e identifica diferentes perspectivas de empoderamento, questionando a que projetos servem. Apresenta a compreensão freireana a respeito da questão, explicitando a concepção de educação crítica que a preside e os princípios que a orientam.
\end{abstract}

Palavras-chave: Empoderamento; Emancipação; Educação; Ação Social.

\begin{abstract}
This article examines the empowerment category discussing the different concepts reviewed by the literature insofar as the aimed objectives and of the logics underlying them. In order to archive this objective, a study of theoretic nature is developed, based upon the analysis of empirical research, reports seeking empowering actions, as well as specifc studies about this concept. Thus it situates historically the origin of the concept and identifies different perspectives of empowering, questioning to which projects they serve. It presents the understanding of this concept based on the work of Paulo Freire, expliciting the conception of critical education that it presides and the principles that guide it.
\end{abstract}

Keywords: Empowerment; Emancipation; Education; Social Action.

\section{Introdução}

A dominação está presente nas sociedades ao longo da história sob diferentes formas. Seu estudo assume centralidade nos campos de Educação e Política, ao se questionar a possibilidade de emancipação do ser humano. Um tema central na discussão sobre emancipação é aquele que se refere ao "empowerment" ou "empoderamento" de sujeitos, individuais e coletivos. Trata-se de categoria de natureza ambígua, cujo entendimento é apresentado sob diferentes formas na literatura.

A inexistência do termo "empoderamento" em dicionários brasileiros recentes e a diversidade de sentidos atribuídos ao termo indicam o caráter plolissêmico e complexo desta categoria. 
O neologismo "empoderamento" está, no entanto, consignado no Dicionário de Língua Portuguesa Contemporânea das Ciências de Lisboa e registrado no Mordebe - Base de Dados Morfológica do Português. O termo é um anglicanismo que significa obtenção, alargamento ou reforço de poder.

$\mathrm{O}$ termo tem sido utilizado em diferentes áreas de conhecimento educação, sociologia, ciência política, saúde pública, psicologia comunitária, serviço social, administração - constituindo-se em ferramenta de governos, organizações da sociedade civil e agências de desenvolvimento em agendas direcionadas para a melhoria da qualidade de vida e dignidade humana de setores pobres, boa governança, maior efetividade na prestação de serviços e responsabilização social (NARAYAN, 2002).

No que pese 0 uso indiscriminado do termo, os debates sobre empoderamento apontam para duas dimensões essenciais a serem consideradas: a educativa e a política, uma vez que visões de mundo e de propósitos sociais diferenciados orientam as distintas concepções e ações de empoderamento.

Neste contexto, um conjunto de questões se impõe para a reflexão: Como a categoria do empowerment tem sido abordada na literatura? Onde radica suas origens? Que lógicas presidem as diferentes perspectivas de empoderamento?

Tais questões são abordadas no presente texto, que se estrutura da seguinte forma: inicialmente há considerações a respeito da origem do conceito de empowerment; num segundo momento, discute-se os usos diversos desta categoria na literatura, referindo-se níveis de empoderamento, suas características e as lógicas que os presidem, enfocando, particularmente, o empowerment proposto por Paulo Freire - empowerment ligado à classe social. Mais do que um trabalho de natureza descritiva, o presente texto pretende desenvolver uma problematização a respeito das questões levantadas.

\section{Origem do conceito}

Embora a utilização crescente do termo empowerment tenha se dado a partir dos movimentos emancipatórios relacionados ao exercício de cidadania - movimento dos negros, das mulheres, dos homossexuais, movimentos pelos direitos da pessoa deficiente - nos Estados Unidos, na segunda metade do século XX, a Tradição do Empowerment (Empowerment Tradition) tem suas raízes na Reforma Protestante, iniciada por Lutero no séc. XVI, na Europa, num movimento de protagonismo na luta por justiça social (HERRIGER, 1997). Neste sentido, conforme assinalam Hermany e Costa (2009), o tema do empoderamento social não é novo, no entanto, o marco histórico que trouxe notoriedade ao conceito foi a eclosão dos novos movimentos sociais contra o sistema de opressão em movimentos de libertação e de contracultura, na década de 1960 do século passado, nos 
Estados Unidos, passando o empowerment a ser utilizado como sinônimo de emancipação social.

No que diz respeito à Tradição do Empowerment com raízes na Reforma Protestante, Hugh Hewitt (2007) destaca que o movimento religioso do monge Martinho Lutero teve conseqüências que foram além da religião. Questionando a interpretação das escrituras então dominantes, e abordando assuntos considerados até então pertencentes ao papado, Lutero, em suas 95 teses, levanta um conjunto de críticas à Igreja e à autoridade papal. Publicada em alemão, a obra oportunizou, aos mais diferentes estratos da sociedade alemã, o conhecimento de suas ideias. Defendendo a livre interpretação da Bíblia, Lutero fez sua tradução para o alemão (Bíblia Luther), possibilitando o contato do povo simples e pouco culto com a bíblia.

A escrita sempre esteve, de alguma forma, associada ao poder. Nas civilizações antigas, os escribas detinham o poder da escrita, pois o domínio dessa tecnologia era de conhecimento restrito. Esse poder os aproximava das classes dominantes (reis, faraós) que sancionavam as informações que deveriam ser registradas. Assim, poucos tinham o poder de decidir o que seria ou não registrado, poucos tinham o poder - a capacidade de fazer - este registro e, portanto, de decifrá-lo.

O processo de Reforma, iniciado por Lutero no século XVI, na Europa, oportuniza, com certas restrições, um empoderamento por parte das pessoas, pois a tradução da Bíblia do latim para o dialeto local - o que contribuiu para a afirmação deste, futuramente, como idioma oficial da Alemanha possibilitou a leitura dos "textos sagrados" entre a comunidade, a qual, por conseguinte, passa a realizar sua leitura e sua hermenêutica, tornando-se sujeito de sua religiosidade.

O resultado desse movimento religioso precisa, no entanto, ser entendido no contexto do efeito multiplicador iniciado pela invenção da imprensa por Gutemberg: a Bíblia, traduzida nas línguas e dialetos locais, torna-se acessível a cada um. Anteriormente ao século XVI, a Bíblia era um manuscrito em latim - língua dominada por uma minoria - do qual havia poucas cópias, que se encontravam fechadas nos conventos e nas igrejas, lidas por uma elite eclesiástica. Em relação ao papel da imprensa, neste contexto, Hewitt (2007) afirma que

Gutemberg amplifica a voz humana de tal modo que ela pode ser ouvida em todo o mundo. Ele forneceu os meios pelos quais uma pessoa pode se comunicar com as massas sem a interferência das estruturas institucionais. Finalmente os indivíduos podiam falar e ninguém podia silencia-los (p. 19).

Assim, empowerment é um conceito que tem raízes na Reforma Protestante. Contemporaneamente, se expressa nas lutas pelos direitos civis, no movimento feminista e na ideologia da "ação social", presentes nas 
sociedades dos países desenvolvidos, na segunda metade do século XX. Nos anos 70, esse conceito é influenciado pelos movimentos de auto-ajuda, e, nos 80 , pela psicologia comunitária. Na década de 1990, recebe o influxo de movimentos que buscam afirmar o direito da cidadania sobre distintas esferas da vida social, entre as quais a prática médica, a educação em saúde, a política, a justiça, a ação comunitária.

\section{Usos diversos da categoria "empoderamento" na literatura}

A produção sobre o tema empowerment ou empoderamento é significativa e se distribui em diferentes disciplinas e práticas profissionais. Um levantamento junto ao Google revela um número significativo de artigos publicados envolvendo a temática sobre empoderamento. A maior parte deles situa-se na área de saúde pública, psicologia comunitária e administração.

Tais textos relatam reflexões em torno do tema ou experiências que objetivaram alguma modalidade de empoderamento. É importante demarcar que o debate conceitual mais acurado sobre a questão tem se dado fora da sociologia e da ciência política, conforme destacam Horochovski e Meirelles (2007). A educação é representada pela obra pioneira de Paulo Freire sobre o tema.

Segundo Sheilds (apud LAWSON, 2001), a vasta produção sobre empoderamento nas várias disciplinas está exigindo uma delimitação conceitual, uma vez que a ambiguidade conceitual tem limitado sua aplicabilidade.

O significado da categoria empowerment, como tem sido traduzido no Brasil, não tem um caráter universal, conforme alerta Gohn (2004). No entanto, de modo geral, os autores concordam que o empoderamento pode ocorrer em diferentes níveis, referindo o empoderamento individual, o empoderamento organizacional e o empoderamento comunitário.

Segundo Wallerstein e Bernstein (apud BAQUERO, 2006), o empoderamento é uma construção em nível individual, quando se refere às variáveis intrafísicas e comportamentais; em nível organizacional, quando se refere à mobilização participativa de recursos e oportunidades em determinada organização; e em nível comunitário, quando a estrutura das mudanças sociais e a estrutura sociopolítica estão em foco.

O empoderamento individual se refere ao nível psicológico de análise. No nível individual, empoderamento refere-se à habilidade das pessoas de ganharem conhecimento e controle sobre forças pessoais, para agir na direção de melhoria de sua situação de vida. Diz respeito ao aumento da capacidade de os indivíduos se sentirem influentes nos processos que determinam suas vidas.

Zimmerman (apud HOROCHOVSKI e MEIRELLES, 2007) refere ser o empoderamento individual também intrapessoal, na medida em que, embora, fortemente influenciado por fatores psicológicos - autoestima, temperamento 
e experiências, o empoderamneto individual é relacional, resultando de percepção que os sujeitos têm de/em suas interações com ambientes e pessoas. Freire em diálogo com Ira Shor (FREIRE e SHOR, 1986) destaca que o empoderamento individual é uma auto-emancipação, fundada numa compreensão individualista de empoderamento, que enfatiza a dimensão psicossocial. Tal noção desenvolve-se na sociedade norte-americana, cuja cultura tem sido cooptada pelo individualismo e pelas noções individuais de progresso, orientada para o self made man (o homem que se faz pelo seu próprio esforço pessoal). A ênfase é no aumento do poder individual, medido em termos do aumento no nível de autoestima, de autoafirmação e de autoconfiança das pessoas. Estratégias voltadas à autoajuda e ao autoaperfeiçoamento estão presentes neste tipo de empoderamento.

O empoderamento organizacional é o empoderamento gerado na e pela organização. Trata-se de uma abordagem do processo de trabalho que objetiva a delegação do poder de decisão, autonomia e a participação dos funcionários na administração das empresas, de modo que as decisões sejam mais coletivas e horizontais.

Nessa perspectiva, empoderar significa "dar ao pessoal autoridade para fazer mudanças no trabalho em si, assim como na forma em que ele é desempenhado" (SLACK et. al. 1997, p. 311). Significa obter o comprometimento dos empregados em contribuir para as decisões estratégicas da empresa, visando melhorar o desempenho da organização em termos de produtividade (CUNNINGHAM e HYMAN, 1999; GUERREIRO FILHO, 2011).

O empoderamento organizacional é passível de ser identificado na transição do processo de produção fordista (produção em série através de atividades rotineiras, repetitivas) para o processo toyotista (atividades em células, trabalho em grupo). Sua finalidade é aumentar a produtividade da empresa. Constitui-se numa alternativa ao paradigma tradicional de gestão, direcionando-se para a desburocratização, descentralização, flexibilização e inovação (HERRENKOHL, JUDSON e HEFNER, 1999; CUNNINGHAM e HYMAN, 1999; WILKINSON, 1998; PFERFFER e DUNLOP, 1990; RODRIGUES e SANTOS, 2004).

O empoderamento comunitário, segundo Perkins e Zimmerman (apud HOROCHOVSKI e MEIRELLES, 2007), é o processo pelo qual os sujeitos atores individuais ou coletivos - de uma comunidade, por meio de processos participativos, desenvolvem ações para atingir seus objetivos, coletivamente definidos. Kleba, Comerlatto e Colliseli (2007), bem como Almeida, Dimenstein e Severo (2010) e Ferreira et. al. (2007) também compartilham deste entendimento a respeito do empoderamento comunitário nos seus textos.

O empoderamento comunitário envolve um processo de capacitação de grupos ou indivíduos desfavorecidos para a articulação de interesses, 
buscando a conquista plena dos direitos de cidadania, defesa de seus interesses e influenciar ações do Estado.

Gohn (2002), em estudo sobre a educação popular na América Latina, refere a importância do método Paulo Freire na década de 1990, precisamente pela sua dimensão de empowerment (empoderamento) dos indivíduos e grupos de uma comunidade. Nas palavras de Gohn (2002),

[...] sua utilização nos anos 90 ocorre - menos pela sua dimensão política-participante - que deu espaço aos movimentos populares e aos militantes de faç̧ões políticopartidárias, nos anos 70-80, para realizarem um trabalho "de base", gerador de consciências críticas no sentido pleno da transformação social, contestador da ordem social vigente; e mais pela sua dimensão de empowerment (empoderamento) dos indivíduos e grupos de uma comunidade - gerando um processo de incentivo às potencialidades dos próprios indivíduos para melhorarem suas condições imediatas de vida, objetivando o "empoderamento" da comunidade, isto é, a capacidade de gerar processos de desenvolvimento autosustentável, com a mediação de agentes externos - os novos educadores - atores fundamentais na organização e o desenvolvimento dos projetos. O novo processo ocorre, predominantemente, sem articulações políticas mais amplas, principalmente com partidos políticos ou sindicatos (p. 72).

A mesma autora adverte, no entanto, que o significado e o resultado da dimensão do empowerment não têm um caráter universal, podendo tanto promover e impulsionar grupos e comunidades (crescimento, autonomia, melhora gradual e progressiva de suas vidas), como, pura e simplesmente, a integração dos excluídos, carentes e demandatários de bens elementares à sobrevivência, serviços públicos, etc., em sistemas precários, que não contribuem para organizá-los, face às características do atendimento oferecido em programas de natureza individual e assistencialista (GOHN, 2004).

Em relação a esta questão, Gohn (2004), assim como Edwards (1999) e Uphoff (1993), defendem a necessidade de que ações de organizações da sociedade civil contribuam, não só para assegurar a sobrevivência de grupos excluídos, mas também na mobilização social, desempenhando um papel mediador entre os grupos excluídos e o governo e outras instâncias de poder, no sentido de empoderá-los, procurando influenciar o processo político geral, exercendo a advocacy dos grupos.

Em oposição a esta perspectiva e numa visão conservadora, Perkins (1995) defende o entendimento de empoderamento como fortalecimento da esfera privada, argumentando a necessidade das associações e comunidades resolverem, por si próprias, seus problemas. Nesse sentido, combate políticas 
e programas estatais de assistência e bem estar social, justificando o descompromisso do Estado nessa área.

O duplo significado que o empowerment pode assumir, segundo Gohn (2004), remete à diferenciação da utilização do termo como verbo transitivo ou intransitivo, conforme assinalado por Labonte (1994). Como verbo transitivo, empoderar envolve um sujeito que age sobre um objeto. Como verbo intransitivo, por sua vez, envolve a ação do próprio sujeito.

Usado transitivamente, empoderar significa dar poder a outro, compartilhando alguns poderes que determinados profissionais devem ter sobre outros. Desta forma, o profissional é visto como agente de empoderamento, e permanece como sendo o ator controlador, definindo os termos da interação. Os indivíduos ou grupos relativamente desempoderados permanecem como objetos da relação, como os receptores da ação externa, numa atitude passiva. A afirmação "precisamos empoderar este ou aquele grupo" reforça a ação de um indivíduo/grupo sobre outro indivíduo/grupo, considerados incapazes de sua própria ação de poder.

Usado como verbo intransitivo, empoderar se refere a um processo através do qual pessoas ganham influência e controle sobre suas vidas e, consequentemente, se tornam empoderadas (WALLERSTEIN e BERSTEIN, 1994). Diferentemente da primeira concepção de empoderamento, que é investir ou dar poder e autoridade a outros, a segunda compreensão envolve tornar os outros capazes, ou auxiliar os outros a desenvolver habilidades para que possam obter poder por seus próprios esforços.

Do ponto de vista de uma educação crítica, os educadores não podem "dar poder às pessoas", mas podem torná-las capazes de aumentar suas habilidades e recursos para ganhar poder sobre suas vidas.

Empoderar como verbo intransitivo configura uma perspectiva emancipatória de empoderamento, processo pelo qual indivíduos, organizações e comunidades angariam recursos que lhes permitem ter voz, visibilidade, influência e capacidade de ação e decisão (HOROCHOVSKI e MEIRELLES, 2007), com o objetivo, conforme destaca Friedmann (1996), de reequilibrar a estrutura de poder na sociedade. Nessa perspectiva de empoderamento, o Estado e a empresa estão sujeitos à responsabilização social, aumentando os poderes da sociedade civil na gestão de seus próprios assuntos (FRIEDMANN, 1996).

Embora historicamente o empoderamento esteja associado a formas alternativas de se trabalhar as realidades sociais, suporte mútuo, formas cooperativas, formas de democracia participativa, autogestão e movimentos sociais autônomos, tendo sido a palavra incorporada ao discurso do desenvolvimento alternativo, ocorreu, segundo progressistas, uma apropriação "indevida" do termo, pelo neoliberalismo.

Empoderar se constitui, hoje, na agenda de vários bancos de desenvolvimento, especialmente do Banco Mundial e do Fundo Monetário Internacional. Documentos são produzidos e divulgados por tais agências a 
respeito da relação entre empoderamento e redução da pobreza e desenvolvimento, bem como, apoiado projetos, com vistas ao empoderamento de sujeitos e comunidades.

Estão presentes neste debate duas perspectivas distintas de empoderamento, tendo como critério a visão acerca da natureza e do papel da sociedade civil: uma, de matriz tocquevilliana e a outra, de inspiração gramsciana, habermaseana e freireana (OSMANI apud HOROCHOVSKI e MEIRELLES, 2007). A primeira concebe a sociedade civil como uma esfera mais ou menos independente do Estado, a segunda, concebe a sociedade civil como espaço público de transformação de pensamentos em ação, espaço de emancipação dos grupos dominados e excluídos. Caudatários desta visão emancipatória de empoderamento direcionam sua crítica à perspectiva do mainstream do desenvolvimento, destacando a necessidade de considerar, entre outros: assimetrias de recursos de poder na sociedade, a universalização da dimensão social dos direitos de cidadania, a valorização de outras dimensões de empoderamento - afetivas, psicológicas, culturais e políticas - que não somente a eficiência econômica, a mobilização política dos grupos e comunidades (ROMANO, 2002). Criticam, ainda, a crença ingênua de que mais informação e descentralização das agências são condições suficientes de empoderamento de grupos.

$\mathrm{Na}$ primeira perspectiva, situam-se as ações de organizações como agências das Nações Unidas e várias ONGs internacionais e pesquisas editadas por tais agências, como as de Narayan (2002), Krishna (2003) e Alsop e Heinsohn (2005). Na segunda perspectiva, situam-se as pesquisas sobre empoderamento emancipatório, dentre as quais destaca-se o trabalho pioneiro de Paulo Freire, nos círculos de cultura, com populações marginalizadas no nordeste brasileiro (FREIRE, 1979, 1981 e 1987).

Freire propõe outra concepção de empowerment, não individual, nem comunitário, nem meramente social, mas um conceito de empowerment ligado à classe social (FREIRE e SHOR, 1986).

\section{Empoderamento segundo Paulo Freire}

Freire propõe outra concepção de empowerment - o empoderamento de classe social. Isso significa na compreensão freireana, que não se trata de um processo de natureza individual. O autor afirma não acreditar na autolibertação; a libertação é um ato social (FREIRE, 1986).

Referindo sua descrença na auto-emancipação pessoal argumenta, em diálogo com Ira Shor, em Medo e Ousadia - o cotidiano do professor (1986), que

Mesmo quando você se sente, individualmente, mais livre, se esse sentimento não é um sentimento social, se você não é capaz de usar sua liberdade recente para ajudar os outros a 
se libertarem através da transformação da sociedade, então você só está exercitando uma atitude individualista no sentido do empowerment ou da liberdade (p. 135).

Isso faz do empowerment muito mais do que invento individual ou psicológico, configurando-se como um processo de ação coletiva que se dá na interação entre indivíduos, o qual envolve, necessariamente, um desequilíbrio nas relações de poder na sociedade.

Na perspectiva freireana, o empoderamento individual, fundado numa percepção crítica sobre a realidade social, é fundamental, mas tal aprendizagem precisa ter relação com a transformação mais ampla da sociedade. A pergunta que se coloca, segundo Freire (2003), é: "a favor de quem e contra quem eles usam sua nova liberdade na aprendizagem e como é que essa se relaciona com os outros esforços para transformar a sociedade [?]" (p. 136).

Nessa perspectiva, o empoderamento, como processo e resultado, pode ser concebido como emergindo de um processo de ação social no qual os indivíduos tomam posse de suas próprias vidas pela interação com outros indivíduos, gerando pensamento crítico em relação à realidade, favorecendo a construção da capacidade pessoal e social e possibilitando a transformação de relações sociais de poder.

Neste sentido, as questões que devem ser respondidas são: Que processo é este? Quais são suas características? O que envolve? Em que princípios se apóia?

O empoderamento envolve um processo de conscientização, a passagem de um pensamento ingênuo para uma consciência crítica. Mas isso não se dá no vazio, numa posição idealista, segundo a qual a consciência muda dentro de si mesma, através de um jogo de palavras num seminário. A conscientização é um processo de conhecimento que se dá na relação dialética homem-mundo, num ato de ação-reflexão, isto é, se dá na práxis (FREIRE, 1979). Conscientizar não significa manipular, conduzir o outro a pensar como eu penso; conscientizar é "tomar posse do real", constituindo-se o olhar mais crítico possível da realidade; envolve um afastamento do real para poder objetivá-lo nas suas relações. Segundo Freire (1986),
Mudamos nossa compreensão e nossa consciência à medida que estamos iluminados a respeito dos conflitos reais da história. A educação libertadora pode fazer isso - mudar a compreensão da realidade. Mas isto não é a mesma coisa que mudar a realidade em si. Não. Só a ação política na sociedade pode fazer a transformação social, e não o estudo crítico em sala de aula (p. 207).

De acordo com Freire (1979), para desenvolver o processo de conscientização são fundamentais o diálogo e uma educação dialógica no 
interior de uma pedagogia situada, isto é, aquela que situa o processo de aprendizagem nas condições reais de cada grupo.

A educação dialógica não é uma técnica de ensinar, é uma postura epistemológica. Assim, o diálogo, enquanto instrumento do processo de conscientização, constitui-se em "um encontro dos humanos para refletirem sobre sua realidade tal como a fazem e re-fazem" (FREIRE e SHOR, 1986, p. 123).

O diálogo não se constitui em mera verbalização de palavras e não tem como objetivo a transferência de conhecimento especializado, mas problematizar a forma oficial do conhecimento, questionando as relações dominantes que o produziram. Dessa forma, envolve um processo de contestação e redescoberta do conhecimento. O diálogo está a serviço de uma educação para a emancipação.

Freire concebe a educação como um ato político, por entendê-la enquanto um projeto social. Concebe a educação como um ato político que envolve ação cultural para a libertação, constituindo-se um projeto de intervenção no mundo. De acordo com Freire (1979), "a educação, como prática de liberdade, é um ato de conhecimento, uma aproximação crítica da realidade" (p. 34), o que envolve um processo de conscientização, conforme já referido.

Freire não desenvolve um método, no sentido pedagógico do termo. 0 método proposto por Freire é, na realidade, a explicitação de uma teoria do conhecimento, que vai na contramão de uma concepção idealista ou empirista de conhecimento. Segundo Andreola (1993):

Contra o subjetivismo, de um lado, e objetivismo mecanicista do outro, que, dissociando e opondo sujeito e objeto, dissociam e opõem prática e teoria, ação e reflexão, Freire proclama a unidade dialética destas na conscientização ( $p$. 37).

O autor destaca que, assim como não se chega à conscientização por uma via psicologista, idealista ou subjetivista, tampouco se chega a ela pelo objetivismo. A tomada de consciência não se dá de forma isolada, mas através das relações que os homens estabelecem entre si, mediados pelo mundo.

Freire (1981) entende a educação como um processo relacional, em que ninguém educa ninguém, ninguém educa a si mesmo, os homens se educam entre si mediados pelo mundo. Dessa forma, em Pedagogia do Oprimido, Freire (1981) é enfático, ao afirmar que "Ninguém liberta ninguém, ninguém se liberta sozinho: os homens se libertam em comunhão" (p. 27). 


\section{À guisa de conclusão}

Segundo Carvalho (2004), empowerment é um conceito múltiplo e complexo, que toma emprestado noções de distintos campos de conhecimento.

A inexistência do termo "empoderamento" na língua portuguesa e a diversidade de sentidos do termo "apoderamento", ilustram a dificuldade de realizar a tradução fidedigna de empowerment para o nosso idioma.

Sendo assim, segundo esse autor, há uma dificuldade refletida no modo com que esta categoria vem sendo traduzida em textos nos idiomas português e espanhol, seja como sinônimo de "empoderamento", "apoderamento" ou de "emancipación". Tais vocábulos, no entanto, têm significados distintos, uma vez que "apoderar" é sinônimo de "dar posse", "domínio de", "apossar-se", "assenhorear-se", "dominar", "conquistar", "tomar posse". São definições que diferem do verbo "emancipar", que significa, por sua vez, "tornar livre, independente" (HOUAISS, 2001).

Sheilds (apud LAWSON, 2001) refere a teoria do empowerment como um enigma, alertando para a complexidade desse conceito que é mais fácil definir pela sua ausência - alienação, impotência, desamparo.

A categoria empoderamento vem sendo utilizada junto a conceitos, tais como, capital social e competência comunitária, entre outros, de forma pouco rigorosa e, muitas vezes, ambígua, em diferentes campos de conhecimento e práticas sociais. Conforme esse texto apontou, diferentes são os conceitos e as práticas de empoderamento que têm orientado trabalhos nas diferentes áreas - educação, política, serviço social, administração, saúde comunitária, economia, psicologia, antropologia.

No entanto, uma análise das diferentes formas em que empoderamento tem sido abordado na literatura evidencia que esta categoria se constitui mais do que um construto de natureza psicológica, estando intimamente implicada nas relações de poder na sociedade.

Conforme os Estudos Interdisciplinares de Comunidades e Ecologia Social (EICOS(b), [s. d.]) destacam, empowerment não é apenas a construção de uma consciência crítica, pelo sujeito, de seu contexto natural, social, cultural e político de vida. Não se resume também a simples capacitação para atuar pela melhoria de padrões em diferentes âmbitos da vida; mas envolve aquisição de poder, isto é, "supõe o vivenciar um processo articulado que integre a construção de uma consciência crítica com a ação, ou o desenvolvimento de capacidade real de intervenção e transformação da realidade" (EICOS (b), [s.d.], [s./p.]). Ele não se reduz a um processo de emancipação individual, envolvendo o desenvolvimento de uma consciência coletiva (EICOS (a) [s. d.]).

Empoderamento, enquanto categoria, perpassa noções de democracia, direitos humanos e participação, mas não se limita a estas. É mais do que trabalhar em nível conceitual, envolve o agir, implicando processos de 
reflexão sobre a ação, visando a uma tomada de consciência a respeito de fatores de diferentes ordens - econômica política e cultural - que conformam a realidade, incidindo sobre o sujeito. Neste sentido, um processo de empoderamento eficaz necessita envolver tanto dimensões individuais quanto coletivas.

Uma educação para a emancipação, concebida, conforme Freire, como ação cultural para a libertação, pode se constituir em instrumento valioso em projetos e ações direcionados ao empoderamento dos sujeitos.

A teoria sócio-política-educativa freireana pode nos ajudar não apenas a entender melhor como funcionam os processos sociais de dominação, mas também a construir respostas necessárias à emancipação humana. Conforme assinala Scocuglia (2009), com base em Freire, as grandes questões matriciais são eminentemente sociais e políticas. A necessidade de compreender a inseparabilidade da educação/política, bem como suas respectivas especificidades, não pode ser emudecida ou desprezada em propostas de formulação contra-hegemônicas.

Rute Vivian Angelo Baquero é PhD. em Educação pela Florida State University, com Pós-doutorado pela Universidade de Buenos Aires, é professora aposentada na UFRGS, tendo coordenado o Programa de Pós-Graduação em Educação da Unisinos e pesquisadora do NUPESAL/UFRGS.

E-mail: rutevivianb@gmail.com

\section{Referências}

ALMEIDA, Kamila S.; DIMENSTEIN, Magda; SEVERO, Ana K. Empoderamento e atenção psicossocial: notas sobre uma associação de saúde mental. Interface (Comunicação, Saúde, Educação), Botucatu, v. 14, n. 34, p. 577-89, jul.-set. 2010.

ALSOP, Ruth; HEINSOHN, Nina. Measuring empowerment in practice: structuring analysis and framing indicators. World Bank Policy Research Working Paper, n. 3510. Washington D.C., feb. 2005.

ANDREOLA, Baiduíno A. O processo de conhecimento em Paulo Freire. Educação e Realidade, Porto Alegre, v. 18, n. 1, p. 32-42, jan.-jun. 1993.

BAQUERO, Rute. Empoderamento: questões conceituais e metodológicas. Redes, Santa Cruz do Sul, v. 11, n. 2, p. 77-93, maio-ago. 2006.

CARVALHO, Sérgio R. The multiple meanings of "empowerment" in the health promotion proposal. Cadernos de Saúde Pública, Rio de Janeiro, v. 20, n. 4, p. 1088-1095, jul.-aug. 2004. 
CUNNINGHAM, Ian; HYMAN, Jeff. The poverty of empowerment? A critical case study. Personal Review, v. 28, n. 3, p. 192-207, 1999.

EDWARDS, Michael. NGO Performance - What Breeds Success?: New evidence from South Asia. World Development, Washington D.C., v. 27, n. 2, p. 361-374, feb. 1999.

EICOS. Estudos Interdisciplinares de comunidades e Ecologia Social. Empoderamento: participação, solidariedade e desenvolvimento (a). Disponível em: <http://www. eicos.psycho.ufrj.br/portugues/empoderamento /empoderamento.htm>. Acesso em: 24 nov. 2005.

Equidade, compromisso social e qualidade de vida (b). Disponível em: <http://64.233.187.104 /search?q=cache:S-Pqj0Zcje8J:openlink.br.inter . net/vllima.orla/bole>. Acesso em: 24 nov. 2005.

FERREIRA, Angela Duarte et. al. Resistência e empoderamento no mundo rural. Estudos, Sociedade e Agricultura, Rio de Janeiro, v. 15, n. 1, p. 123159, abr. 2007.

FREIRE, Paulo. Conscientização. São Paulo: Cortez e Moraes, 1979.

Ação cultural para a libertação e outros escritos. Rio de Janeiro: Paz e Terra, 1987.

. Pedagogia do oprimido. Rio de Janeiro: Paz e Terra, 1981.

FREIRE, Paulo; SHOR, Ira. Medo e ousadia - o cotidiano do professor. Rio de Janeiro: Paz e Terra, 1986.

FRIEDMANN, John. Empowement: uma política de desenvolviemnto alternativo. Celta: Oeiras, 1996.

GOHN, Maria da Glória. Educação popular na América Latina no novo milênio: impactos do novo paradigma. ETD - Educação Temática Digital, Campinas, v. 4, n. 1, p. 53-77, dez. 2002. Disponível em: <http://www.bibli.fae.unicamp.b r/etd/AR03.pdf>. Acesso em: 30 mar. 2005.

. Empoderamento e participação da comunidade em políticas sociais. Saúde e Sociedade, São Paulo, v. 13, n. 2, p. 20-31, maio-ago. 2004.

GUERREIRO FILHO, Antônio. O poder da camisa branca. São Paulo: Ed. Futura, 2011. 
HERMANY, Ricardo; COSTA, Dartagnan Limberger. A necessária superação do modelo representativo hegemônico na construção do empoderamento social local. Revista do Direito, Santa Cruz do Sul, v. 32, n. 2, p. 78-91, jul.-dez. 2009. Disponível em: <https://online.unisc.br/seer/index.php./direito/article/ view/1189/888>. Acesso em: 03 out. 2011.

HERRENKOHL, Roy C.; JUDSON, G. Thomas; HEFFNER, Judith A. Defining and measuring employee empowerment. Journal of Applied Behavioral Science, Arlington, v. 35, n. 3, p. 373-389, sep. 1999.

HERRIGER, Norbet. Empowerment in der sozialen arbeit. Stuttgart: Eine Einfuhrung, 1997.

HEWITT, Hugh. Blog: entenda a revolução que vai mudar o seu mundo. Rio de Janeiro: Thomas Nelson, 2007.

HOROCHOVSKI, Rodrigo R.; MEIRELLES, Giselle. Problematizando o conceito de empoderamento. In: Seminário Nacional Movimentos Sociais, Participação e Democracia. Florianópolis, 2., 2007.

HOUAISS, Antônio. Dicionário Houaiss da língua portuguesa. Rio de Janeiro: Objetiva, 2001.

KLEBA, Maria Elizabeth; COMERLATTO, Dunia E; COLLISELI, Liane. Promoção do empoderamento com conselhos gestores de um polo de educação permanente em saúde. Texto Contexto Emfermagem, Florianópolis, v. 16, n. 2, p. 335-342, abr.-jun. 2007.

KRISHNA, Anirudh. Measuring rings empowerment: an analytic framework. Washington D. C.: World Bank, 2003.

LABONTE, Ronald. Health promotion and empowerment: reflections on professional practice. Health Education Quarterly, New York, v. 21, p. 253268, 1994.

LAWSON, Aleta. Freedom to be one's self: appalachian women's perspectives on empowerment, Blacksburg, Virginia - The Virginia Polytechnic, 2001. Disponível em: <http:// scholar.lib.vt.edu/theses/available/etd-05252001142531/unrestricted/ secondfinaldoc.p df>. Acesso em: 20 mar. 2005.

NARAYAN, Deepa. Empoderamiento y redución de la pobreza: libro de consulta. Coimbra: World Bank, Alfa Ômega, 2002. 
PERKINS, Douglas D. Speaking truth to power: empowerment ideology as social intervention and policy. American Journal of Community Psychology, New York, v. 23, n. 5, p. 765-794, oct. 1995.

PFERFFER, Isobel; DUNLOP, Jane. Increasing productivity through empowerment. Supervisory Management, p. 8-17, jan. 1990.

RODRIGUES, Claudia Ribeiro; SANTOS, Fernando Almada. Empowerment: a case study in manufacturing companies. Gestão e Produção, São Carlos, v. 11, n. 2, maio-ago. 2004. Disponível em: <http://www.scielo.br/scielo.php?sc ript $=$ sci_arttext $\&$ pid $=$ S0104-530X2004000200012\&1>. Acesso em: 06 maio 2005.

ROMANO, Jorge O. Empoderamento: enfrentemos primeiro a questão do poder para combater juntos a pobreza. In: International Workshop Empowerment and Right Based approach in Fighting Poverty Together. Rio de Janeiro, 2002.

SCOCUGLIA, Afonso Celso. A pedagogia social de Paulo Freire como contraponto da pedagogia globalizada. In: SOUZA NETTO, João de; SILVA, Roberto; MOURA, Rogerio (Orgs.) Pedagogia Social. São Paulo: Expressão e Arte Editora, 2009. p. 225-239.

SLACK, Nigel et. al. Administração da produção. São Paulo: Atlas, 1997.

UPHOFF, Norman T. Grassroots organizations and NGOs in Rural Development: Opportunities with diminishing stats and expanding markets. World Developmend, Washington D.C., v. 21, n. 4, p. 607-622, apr. 1993.

WALLERSTEIN, Nina; BERNSTEIN, Edward. Introduction to community emporwerment, participation, education, and health. Health Education Quarterly: Special Issue Community Emporwerment, Participatory Education, and Health, parte I, v. 21, n. 2, p. 141-170, 1994.

WILKINSON, Adrian. Empowerment: theory and practice. Personnel Review, Bradford, v. 27, n. 1, p. 40-56, 1998.

Texto recebido em 27/03/2012.

Aprovado em 17/04/2012. 